\title{
Treatment Costs for Glioblastoma Multiforme in Nova Scotia
}

\author{
Ivar Mendez, Philip Jacobs, Andrea MacDougall, Margarita Schultz.
}

\begin{abstract}
Background: Glioblastoma Multiforme (GBM) is the most common and malignant brain tumor in adults. The median survival in patients harboring this neoplasm is 12 months irrespective of any form of therapy. Health care costs of illnesses with high mortality rates, such as GBM, are of particular interest in times of constrained health care resources. No information regarding costs for the treatment of patients with GBM is available in Canada. The aim of this study was to conduct an analysis of the costs of treatment of GBM in Nova Scotia. Methods: Patients with histologically proven GBM during a three year period (1996-1998) in Nova Scotia were included in the study. Analysis was based on hospital costs supplemented by data on additional medical services received following discharge for the primary intervention. Results: The mean cost of medical care per patient from the time of diagnosis to death was $\$ 17,149$. The highest costs were related to hospitalization with ward costs alone accounting for $48 \%$ of all costs. Radiotherapy costs were $25 \%$, surgery costs were $16 \%$ and chemotherapy costs were $7 \%$ of all costs. Costs for diagnostic procedures were $6 \%$ of the total costs. Conclusion: Our data reflect the costs and practice pattern in the treatment of GBM in Nova Scotia and may be of value as an initial attempt to analyze costs of treatment of GBM in Canada.
\end{abstract}

RÉSUMÉ: Les coûts du traitement du glioblastome multiforme en Nouvelle-Écosse. Introduction: Le glioblastome multiforme (GBM) est la tumeur cérébrale la plus fréquente et la plus maligne chez les adultes. La survie médiane chez les patients porteurs de cette tumeur est de 12 mois, quel que soit le mode de traitement. Les coûts du traitement de maladies ayant un taux élevé de mortalité comme le GBM ont un intérêt particulier en période de contraintes budgétaires dans le domaine de la santé. Il n'existe pas d'information sur les coûts du traitement des patients atteints de GBM au Canada. Le but de cette étude était d'effectuer une analyse des coûts du traitement du GBM en Nouvelle-Écosse. Méthodes: Les patients ayant un GBM prouvé par anatomopathologie pendant une période de trois ans (1996-1998) en Nouvelle-Écosse sont inclus dans l'étude. L'analyse était basée sur les coûts hospitaliers et les coûts extrahospitaliers à la suite de l'intervention initiale. Résultats: Le coût moyen des soins médicaux par patient à partir du moment du diagnostic jusqu'au décès était de $\$ 17,149$. Les frais les plus élevés étaient attribuables à l'hospitalisation, les frais d'hébergement étant responsables de $48 \%$ de tous les coûts. Les coûts de la radiothérapie constituaient $25 \%$ du total, la chirurgie $16 \%$ et la chimiothérapie $7 \%$. Les coûts reliés à la démarche diagnostique étaient de $6 \%$ du total. Conclusion: Nos données reflètent les coûts et le profil de pratique concernant le traitement du GBM en Nouvelle-Écosse et pourraient être utiles comme étape initiale d'une analyse des coûts de traitement du GBM au Canada.

Can. J. Neurol. Sci. 2001; 28: 61-65

Glioblastoma multiforme (GBM) is the most common primary brain tumor in adults and accounts for about $2.5 \%$ of all cancer deaths. ${ }^{1}$ Although approximately 2300 individuals per year develop a brain tumor in Canada, ${ }^{2}$ the incidence of GBM in the country is not known. A recent study in Nova Scotia reported an incidence of GBM of 2.1/100,000 per year. $^{3}$ The standard treatment for a GBM is neurosurgery (resection or biopsy) followed by radiotherapy and, in some cases, systemic chemotherapy. However, GBM is a highly aggressive neoplasm and the median survival in individuals harboring this tumor is 12 months irrespective of any form of therapy. ${ }^{4}$ Novel therapies such as immunotherapy, gene therapy, the use of antiagiogenesis compounds and local chemotherapy using implantable biodegradable polymers (Gliadel) are currently being developed. The cost of these types of therapies could be substantial but there

From the Department of Surgery, Division of Neurosurgery, Queen Elizabeth II Health Sciences Centre and Dalhousie University, Halifax, Nova Scotia (IM, AM), Department of Public Health Sciences, University of Alberta and Health Institute of Health Economics, Edmonton, Alberta (PJ), Pharm Access, Inc, Montreal, Quebec (MS), Canada

ReCeived April 13, 2000. AcCePted infinalform September 20, 2000 Reprint requests to: Ivar Mendez, Queen Elizabeth II Health Sciences Centre, Halifax Infirmary, 1796 Summer Street, Room \#3806, Halifax, Nova Scotia, Canada B3H 3A7 
is little information in the literature regarding the cost of treatment of patients with GBM with standard therapy. Such information would be important in assessing the cost effectiveness of treating a patient with GBM with alternative therapies as they become available.

Although some studies are available regarding the costs for treatment of brain tumors, ${ }^{5-10}$ few studies have analyzed the costs for high grade gliomas. ${ }^{5,8,9}$ No information regarding cost for the care of patients diagnosed with GBM is available in Canada and the results of the foreign studies are not directly applicable as clinical practice patterns and the health care system in Canada are distinctively different. As financial resources within our health care system continue to be strained, the assessment of costs for the care of our patients is crucial. The purpose of this study was to conduct an analysis of the costs of standard treatment therapies for histologically proven GBM from the time of diagnosis until death at the QEII Health Sciences Centre in Halifax, which is the only neurosurgical center in the province of Nova Scotia. Our analysis is based on the in-hospital costs supplemented by data on additional medical services received following discharge for the primary intervention. Our data reflect actual practice rather than protocol-driven care. Furthermore, it provides a picture of care for an entire provincial population, since virtually all Nova Scotia residents with GBM are treated in the Halifax neurosurgical service.

\section{Patient COHORT AND METHODS}

The inclusion criteria in our analysis was histologically proven GBM. All patients with brain tumors in the province of Nova Scotia are referred to the Queen Elizabeth II Health Sciences Centre for histological diagnosis. At the time of this analysis, standard practice for the treatment of GBM included surgery (craniotomy for resection or stereotactic biopsy), radiation therapy and, in some cases, chemotherapy. All visits to the Cancer Center for radiation therapy and chemotherapy were included in the cost calculations. Although carmustine (BCNU) was used as the main chemotherapeutic agent, costs for different agents or combination of drugs were also included in the analysis. All Nova Scotia residents with proven GBM who were diagnosed in 1996, 1997, and 1998 were included in our study. Data on patient characteristics and treatment at the Queen Elizabeth II Health Sciences Centre was collected retrospectively from patient charts. Data on additional hospitalizations, patient visits to emergency rooms and doctors offices outside the hospital were also collected from provider contact. We organized the utilization data into specific resource categories (Appendix A).

We developed unit costs for each service based on data from local sources. These sources are outlined in Appendix A. Using patient-specific utilization and unit cost data, we derived a cost for each patient for each of the service categories. The costs are presented in the form of descriptive statistics. We report on central tendencies (mean, median and standard deviation), as well as on indicators of high cost outliers.

\section{RESULTS}

\section{Patients}

A total of 61 patients met the inclusion criteria of the study.
Histological confirmation of a GBM was available for all patients. The demographic characteristics of this group of patients is presented in Table 1. The average patient age was 64 years with a range of 39-90 years. There were 39 males $(64 \%)$ and 22 females $(36 \%)$. The average time from diagnosis to death was 206 days with a standard deviation of 189 days. The minimum time of survival from diagnosis was two days and the maximum was 831 days. The distribution of survival times is shown in Table 2 .

\section{Costs}

The mean cost of medical care per patient from the time of diagnosis to death was $\$ 17,149$ with a range of $\$ 4,679$ to $\$ 36,342$. The breakdown of costs per patient is shown in Table 3 . The highest costs were related to hospitalization with ward costs alone accounting for $48 \%$ of all costs. The costs for surgical intervention (craniotomy for resection or stereotactic biopsy) accounted for $16 \%$ of all mean costs (Table 3). Total hospital costs for patients undergoing craniotomy for resection were $\$ 20,559$ versus $\$ 14,782$ for patients in whom a stereotactic biopsy was performed (Table 4 ). The higher costs for craniotomy were related to a longer stay in hospital (a mean of 14 days for craniotomy versus a mean of nine days for stereotactic biopsy) and higher costs of supplies related to the procedure (Appendix A). Cost for diagnostic procedures (radiology and laboratory tests) were very modest and accounted for only $6 \%$ of total costs.

Radiotherapy costs accounted for $25 \%$ of all costs (Table 3 ) while chemotherapy costs (medical oncologists and chemotherapy drugs) were $7 \%$ of all costs. Patients that received surgery alone, either a craniotomy for resection $(n=5)$ or a stereotactic biopsy $(n=13)$, had mean costs of $\$ 11,921$. Patients receiving postoperative radiation had a mean cost of $\$ 18,241$ while patients receiving postoperative radiation and chemotherapy had higher costs with a mean of $\$ 22,447$ (Table $5)$.

The mean costs for survival time are shown in Table 6 . The mean cost per survival day for patients that survived up to 179 days was $\$ 79$. For patients that survived up to 359 days the cost was $\$ 49$ per day and for patients that survived up to 720 days, the daily cost was $\$ 34$.

\section{DISCUSSION}

This study has analyzed the direct costs of treating patients with a proven histological diagnosis of GBM during a three year period in the province of Nova Scotia. Cost analysis of treatment of specific clinical entities is important as constraints in health expenditure continue to increase. Health care costs of illnesses with high mortality rates, such as GBM, are of particular interest in times of constrained health care resources. ${ }^{11,12}$ In the present study $80 \%$ of the patients died within one year of diagnosis. We have found that the mean cost of treatment of patients diagnosed with GBM in the province of Nova Scotia is $\$ 17,149$ (range $\$ 4,679$ to $\$ 36,342$ ). The indirect costs related to the patient's loss of income and the economic impact on their families and community are difficult to determine and have not been analyzed. A United States study suggests that the indirect costs for cancer in the central nervous system are approximately 6.5 times the direct costs. ${ }^{13}$

When the survival time is considered, the daily costs of 
Table 1: Characteristics of Patients and Treatments $(\mathrm{N}=61)$

\begin{tabular}{lr}
\hline Variable & Frequency/Value \\
Mean age - years & 64.3 \\
Range - years & $39-90$ \\
Sex & \\
$\quad$ Male & $39(64 \%)$ \\
Female & $22(36 \%)$ \\
\hline
\end{tabular}

Table 2: Survival Times

\begin{tabular}{lc}
\hline Mean survival days & 206 \\
(Standard deviation) & 189 \\
Survival Categories & Numberof Patients \\
1 day to 90 days & 21 \\
91 days to 180 days & 11 \\
181 days to 270 days & 11 \\
271 days to 360 days & 6 \\
361 days to 720 days & 11 \\
More than 720 days & 1 \\
\hline
\end{tabular}

Table 4: Total Cost by Procedure

\begin{tabular}{llll}
\hline $\begin{array}{l}\text { Number } \\
\text { of cases }\end{array}$ & Procedure & Mean & $\begin{array}{l}\text { Standard } \\
\text { Deviation }\end{array}$ \\
25 & Craniotomy & $\$ 20,559$ & $\$ 8,224$ \\
36 & Biopsy & $\$ 14,782$ & $\$ 7,195$ \\
\hline
\end{tabular}

Table 5: Total Cost of Therapy

\begin{tabular}{llll}
\hline $\begin{array}{l}\text { Number } \\
\text { of cases }\end{array}$ & Therapy & Mean & $\begin{array}{l}\text { Standard } \\
\text { Deviation }\end{array}$ \\
18 & Surgery & $\$ 11,921$ & $\$ 6,577$ \\
32 & Surgery + Radiation & $\$ 18,241$ & $\$ 7,296$ \\
11 & Surgery + Radiation & $\$ 22,447$ & $\$ 8,451$ \\
& + Chemotherapy & & \\
\hline
\end{tabular}

Table 6: Total Cost by Survival

\begin{tabular}{lllll}
\hline $\begin{array}{l}\text { Number } \\
\text { of cases }\end{array}$ & $\begin{array}{l}\text { Days of } \\
\text { Survival }\end{array}$ & Mean & $\begin{array}{l}\text { Standard } \\
\text { Deviation }\end{array}$ & $\begin{array}{l}\text { Mean cost } \\
\text { perday }\end{array}$ \\
32 & $0-179$ & $\$ 14,204$ & $\$ 7,282$ & $\$ 79.00$ \\
17 & $180-359$ & $\$ 17,701$ & $\$ 7,171$ & $\$ 49.00$ \\
12 & $360-720$ & $\$ 24,221$ & $\$ 7,260$ & $\$ 34.00$ \\
\hline
\end{tabular}

Table 3: Summary of Cost Per Patient

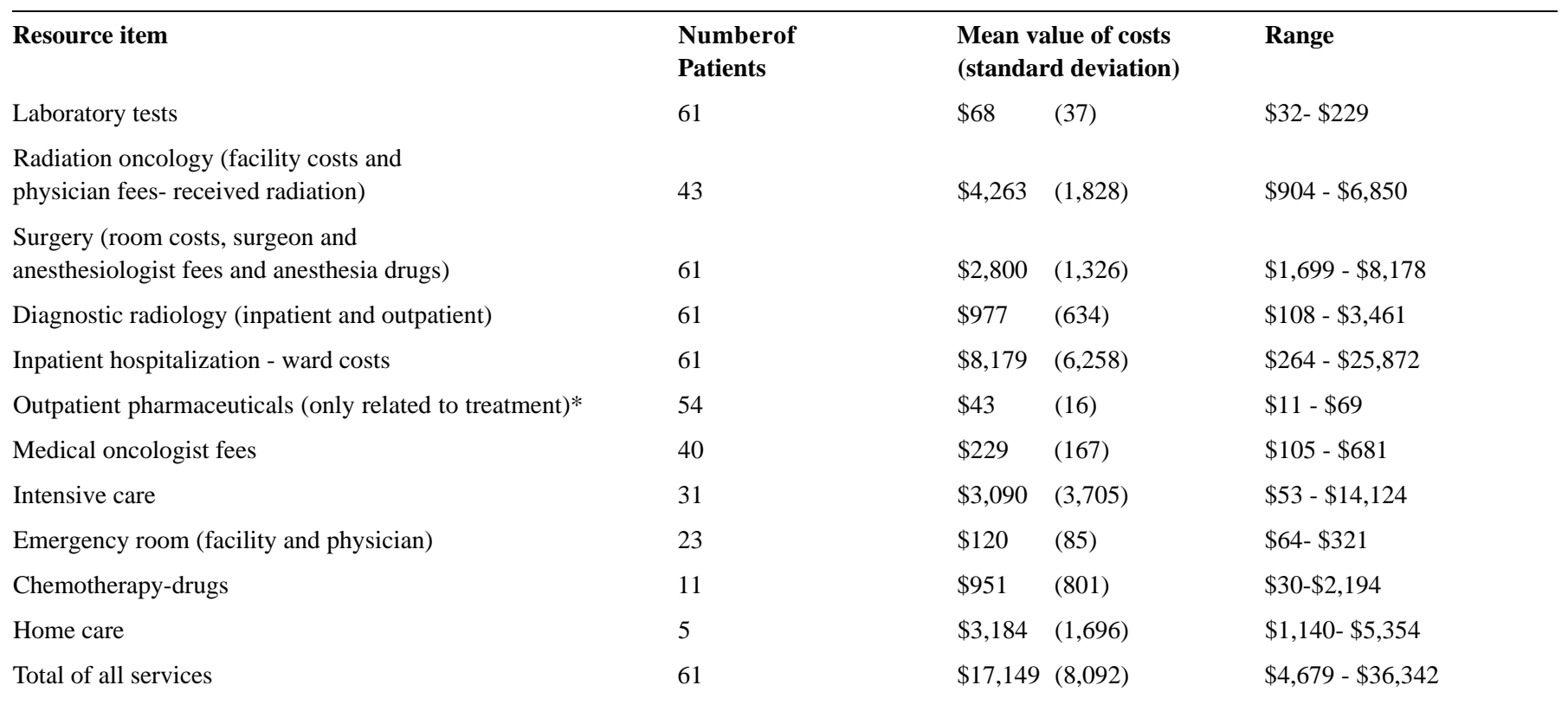

*Only includes decadron, sulcrate and dilantin 
treatment decreased with longer survival times. A patient surviving up to six months cost $\$ 79$ per day while survival prolonged to one year results in costs decreased to $\$ 49$ per day. In this study, the majority of patients died within one year of diagnosis and the decrease in costs with survival time reflects the higher costs of initial treatment. The initial treatment period, which included patient hospitalization and surgery, accounted for the majority of costs (64\%). This observation has also been made by a recent study looking at cost of care of high-grade astrocytomas. $^{5}$

The costs of surgical intervention were higher if the patient had a craniotomy for tumor resection versus a stereotactic biopsy. This observation is relevant to cost-effectiveness of surgery in GBM in view of the controversy related to the survival benefits of tumor resection versus biopsy. ${ }^{14}$ The higher costs for craniotomy are due mainly to increased hospitalization time (14 days versus nine days for stereotactic biopsy) and higher costs of supplies related to the procedure $(\$ 1,144$ versus $\$ 64$ for a stereotactic biopsy). The costs of anesthesia drugs are included in the calculation of surgical supplies. In our center, stereotactic biopsy is performed using sedation and local anesthesia.

Radiotherapy costs were $25 \%$ of the total costs of treatment and $71 \%$ of the patients received radiotherapy postoperatively. In this study, radiotherapy appears to be a cost-effective treatment in view of the relatively moderate costs and the available evidence showing that postoperative radiotherapy is more effective in the treatment of GBM than surgery alone. ${ }^{15-18}$ The relatively low costs of radiotherapy in our study likely relates to low hospitalization rates. In the majority of cases, radiotherapy is provided as an outpatient service. In contrast, a recent British study looking at the costs of the treatment of malignant glioma at a neuro-oncology clinic showed that the costs of radiotherapy were twice the costs of surgery and neurosurgical beds combined. ${ }^{9}$ These higher costs were associated with in-hospital stays of 14 days for patients receiving radical radiotherapy and seven days for patients receiving palliative radiotherapy.

Only $18 \%$ of patients in this study received chemotherapy, accounting for $7 \%$ of all costs per patient. The relatively low use of chemotherapy reflects the modest impact of chemotherapy in the treatment of GBM ${ }^{18}$ and the practice pattern in Nova Scotia. Canadian studies have reported on the cost-effectiveness of chemotherapy for other types of cancers such as metastatic nonsmall-cell lung cancer. ${ }^{19}$ However, no studies are available regarding costs of chemotherapy for brain tumors in Canada. As new drugs and novel therapies, such as local chemotherapy using implantable biodegradable polymers impregnated with BCNU, for brain tumors become available, ${ }^{20,21}$ analysis of costeffectiveness of these interventions would need to be compared with the cost of systemic chemotherapy.

In summary, the results of this study reflect the cost and practice pattern in the treatment of GBM in Nova Scotia and may be of value as an initial attempt to analyze the costs of treatment of GBM in Canada, as no information regarding cost for the care of these patients in Canada is currently available.

Future analysis of both the direct and indirect costs of patients with GBM and the impact of resource utilization in quality of life and clinical effectiveness are of paramount importance in determining the cost-effectiveness of neurosurgical intervention for GBM.

\section{ACKNOWLEDGEMENTS}

This study was supported in part by a grant from Rhone-Poulence Rorer. The authors thank Dr. Vivek Metha for his review of the manuscript, Tanya Acorn for preparation of the manuscript and Sharon Smith for her assistance in data collection.

\section{REFERENCES}

1. National Cancer Institute of Canada. Canadian Cancer Statistics 1999. Toronto, Canada, 1999

2. Williams B, Dewar R, Kirby S, Mendez I. The geographic distribution of glioblastoma multiforme in Nova Scotia. Can J Neurol Sci 1998; 25(Suppl. 1):S69.

3. Mehta V, Mendez I. Intracranial astrocytomas: concepts and therapy. Can J Diagnosis 1999; 9:126-136.

4. Scott JN, Rewcastle NB, Brasher MA, et al. Which glioblastoma multiforme patient will become a long- term survivor? A population- based study. Ann Neurol 1999; 46:183-187.

5. Silverstein MD, Terrance CL, Harmsen WS. High grade astrocytomas: resource use, clinical outcomes, and cost of care. Mayo Clin Proc 1996; 71:936-944.

6. Rutigliano MJ, Lunsford LD, Kondziolka D. The cost effectiveness of stereotactic radiosurgery versus surgical resection in the treatment of solitary metastatic brain tumors. Neurosurgery 1995; 37:445-455.

7. Penar PL, Wilson JT. Cost and survival analysis of metastatic cerebral tumors treated by resection and radiation. Neurosurgery 1994; 34:888-894

8. Konski A, Bracey P, Weiss S, et al. Cost-utility analysis of a malignant glioma protocol. Int J Radiat Oncol Biol Phys 1997; 39:575-578.

9. Latif ZF, Signorini D, Gregor A, et al. The cost of managing patients with malignant glioma at a neuro- oncology clinic. $\mathrm{Br} \mathrm{J}$ Neurosurgery $1997 ; 12: 118-122$.

10. Mehta M, Noyes W, Craig B, et al. A cost-effectiveness and costutility analysis of radiosurgery vs. resection for single brain metastases. Int J Radiat Oncol Biol Phys 1997; 39:445-454.

11. Scitovsky AA, Carpon AM. Medical care at the end of life: the interaction of economics and ethics. Ann Rev Public Health 1986; 7:59-75.

12. Lubitz JD, Riley GF. Trends in medicare payments in the last year of life. N Eng J Med 1993; 328:1092-1096.

13. Hartunian NS, Smart CN, Thompson MS. The incidence and economic costs of cancer, motor vehicle injuries, coronary heart disease, and stroke: a comparative analysis. Am J Public Health 1980; 70:1249-1260.

14. Simpson JR, Horton J, Scott C, et al. Influence of location and extent of surgical resection on survival of patients with glioblastoma multiforme: results of three consecutive radiation therapy oncology group (RTOG) clinical trials. Int J Radiat Oncol Biol Phys 1993; 26:239-244.

15. Leibel SA, Scott CB, Loeffler JS. Contemporary approaches to the treatment of malignant gliomas with radiation treatment. Sem Oncol 1994; 21:198-219.

16. Whittle IR. Management of primary malignant brain tumor. J Neurol Neurosurg Psychiatry 1996; 60:2-5.

17. Fine HA. The basis for current treatment recommendations for malignant gliomas. J Neurooncol 1994; 20:11-20.

18. Walker MD, Alexander E Jr. Hunt WE, et al. Evaluation of BCNU and /or radiotherapy in the treatment of anaplastic gliomas: a cooperative clinical trial. J Neurosurg 1978; 49:333-343.

19. Berthelot JM, Will BP, Evans WK, et al. Decision framework for chemotherapeutic interventions for metastatic non-small-cell lung cancer. J Natl Cancer Inst 2000; 92:1321-1329.

20. Brem H, Piantadosi S, Burger PC, et al. Placebo- controlled trail of safety and efficacy of intraoperative controlled delivery by biodegradable polymers of chemotherapy for recurrent gliomas. Lancet 1995; 345:1008-1012.

21. Valtonen S, Timonen U, Toivanen P, et al. Interstitial Chemotherapy with Carmustine-loaded polymers for high-grade gliomas: a randomized double-blind study. Neurosurgery 1997; 41:44-49. 
Appendix A: Service categories and unit costs for glioblastoma cases

\begin{tabular}{ll}
\hline Type of service & Method of measurement \\
\hline Inpatient days & $\begin{array}{l}\text { Direct nursing and supplies (including drugs) - costs } \\
\text { from a Nova Scotia teaching hospital. }\end{array}$ \\
Operating room costs & Direct nursing cost per hour of OR time \\
& Supplies directly estimated per procedure \\
Laboratory tests & $\begin{array}{l}\text { Recovery room costs:1 hour nursing } \\
\text { Total direct costs per workload unit in a Nova Scotia }\end{array}$ \\
teaching hospital \\
Radiology costs
\end{tabular}

\section{Inpatient physician fees \\ - surgeon}

- anesthesiologist

\section{Outpatient physician fees}

\section{Emergency room \\ - facility fees \\ - physician fees}

\section{Chemotherapy}

Medical oncology visit

Outpatient pharmacy costs

\section{Radiation oncology \\ - facility cost \\ - oncologist visit}

Provincial schedule of benefits. Craniotomy (code 14.29.c)

Provincial schedule of benefits; load factor for specific procedures and times.

Provincial schedule of benefits.

Cost per visit, nursing and ER operating costs Provincial schedule of benefits.

Cost of drugs to hospital. For drugs taken orally, a publicly set dispensing fee (\$8.85) is added. For intravenously administered drugs, a pharmacy preparation and nursing administration cost of $\$ 22$ per hour is added.

Cost per consult (for those not receiving chemotherapy), and cost per medication administration ( for those receiving chemotherapy. ) As per provincial billing schedule.

Cost of individual drugs from hospital pharmacy. Cost per patient is based on assumed dosing schedule. Pharmacy dispensing fee based on the provincial pharmacist reimbursement rate.

Facility costs - provincial estimate Based on provincial schedule of benefits
Cost

Ward per diem:

ICU per diem:

264.00

Nursing per hour:

$1,284.00$

Other support staff:

Craniotomy, per case:

Biopsy, per case

Craniotomy:

37.00

7.50

Biopsy:

$1,144.00$

Recovery:

Venipuncture:

routine bloodwork:

4.31

dilantin level:

28.02

group and cross match:

14.90

11.96

\section{CT scan:}

un-enhanced:

112.22

enhanced:

combined:

118.76

157.24

MRI:

non-enhanced:

112.97

enhanced:

128.42

Major consult $\quad 71.39$

daily visit: $\quad 24.84$

craniotomy: $\quad 1,118.00$

biopsy: $\quad 1,218.00$

post-operative per day: $\quad 24.84$

Per hour $\quad 130.00$

Per operation (average) $\quad 473.00$

$\begin{array}{ll}\text { Per visit } & 24.84\end{array}$

Facility fee per visit $\quad 45.00$

Per visit $\quad 19.32$

Drug cost

Pharmacist fee: $\quad 8.85$

IV administration (per dose): $\quad 22.00$

Consult

105.00

Administration visits

Drug cost

Pharmacy fee

(per drug dispensed)

Per visit

175.00

First visit

60.86

Other visits (per visit) 